\title{
The Application of Healing Garden on The Mother and ChILd HOSPITAL's DESIGN STRATEGY
}

\section{Penerapan Healing Garden Pada Strategi Desain Rumah Sakit Ibu DAN ANAK}

\author{
Desi Nur Aini ${ }^{1 *}$, Avi Marlina ${ }^{2}$, Titis Srimuda Pitana ${ }^{3}$ \\ Program Studi Arsitektur, Fakultas Teknik, Universitas Sebelas Maret ${ }^{1}$ \\ desinuraini8@gmail.com \\ Program Studi Arsitektur, Fakultas Teknik, Universitas Sebelas Maret ${ }^{2}$ \\ Program Studi Arsitektur, Fakultas Teknik, Universitas Sebelas Maret ${ }^{3}$
}

\begin{abstract}
Some researches show that healing environment has big impact for patient's health and well-being. Healing environment is a design concept that has environment as its dominant issue. Nature and its element, such as natural lighting, air circulation, and silence could make patient become calmer and reduce patient's stress and depression. These natural elements could be realized by applying healing garden. The method of this research is triangulation of source method by showing qualitative and descriptive data. The result of this research is the principle application of healing garden in design. The applications of healing garden could stimulate human's sense, such as sense of sight by applying various colours, materials, and natural lighting, sense of hearing by applying artificial pond and noise control, sense of touch by applying vegetation which sensitive of touch, sense of taste by applying vegetation that could be eaten, and sense of smell by applying flowers. The garden should be easy to find and recognize by applying sign and symbol. The garden will be provided with accessibility for patient by applying ramp and the width of the road, healing garden in front of the hospital and certain area, and also provided place for animals.
\end{abstract}

Keywords: Hospital, mother and child, healing, environment, garden

\section{PENDAHULUAN}

Rumah sakit ibu dan anak merupakan salah satu jenis rumah sakit yang khusus memberikan pelayanan kesehatan terhadap alat reproduksi wanita serta anak-anak dengan usia di bawah 12 tahun. Fungsi utama Rumah Sakit Ibu dan Anak meliputi bidang pencegahan (preventif), pengobatan (kuratif), dan pemulihan (rehabilitasi) terhadap pasien jika dirasa membutuhkan (Kementerian Kesehatan, 2010).

Gangguan psikologis sangat mudah terjadi pada wanita yang baru saja melakukan proses persalinan dan pada anak-anak yang melakukan suatu prosedur medis di rumah sakit ibu dan anak. Selama ini, rumah sakit selalu identik sebagai tempat berkumpulnya orang sakit. Banyaknya kegiatan serta pelayanan di Rumah sakit seringkali menimbulkan stress, depresi, dan kecemasan terhadap pasien. Tekanan psikologis ini jika diabaikan dapat berdampak buruk bagi kesehatan fisik pasien dan mempengaruhi proses penyembuhan (Kurniawati, 2007).

Menurut World Health Organization (WHO) sehat bukan hanya kondisi saat hilangnya rasa sakit dan rasa lemah, akan tetapi merupakan sebuah kondisi dimana fisik, mental dan sosial dalam keadaan yang sejahtera. Menurut Kaplan (1993) dalam Kurniawati (2007) disebutkan bahwa faktor penentu kesembuhan manusia terdiri dari $40 \%$ faktor lingkungan, 
$10 \%$, faktor medis, $20 \%$ faktor genetis dan $30 \%$ faktor lainnya. Suatu konsep pendekatan desain yang erat kaitannya dengan lingkungan penyembuhan adalah healing environment.

Kajian healing environment menempatkan alam sebagai faktor utama dalam menunjang proses penyembuhan. Alam dan elemen alami seperti pencahayaan alami, penghawaan alami, dan ketenangan dipercaya dapat menimbulkan ketenangan dalam diri pasien dan menghindarkan pasien dari perasaan stress dan depresi (Zhafran, Hardiyati, \& Pramesti, 2017).

Menurut Ulrich (1984) dalam Schaller (2012) akses visual ke alam diperlukan untuk menstimulus kesehatan dan mengurangi stress. Ulrich telah melakukan penilitian tentang efek dari tampilan jendela rumah sakit pada pemulihan dari operasi perut. Studi Ulrich berfokus pada pasien yang bisa melihat pohon dengan yang melihat dinding bata melalui jendela kamar. Studi tersebut menunjukkan bahwa pasien-pasien yang dapat melihat pohon membutuhkan lebih sedikit obat penghilang rasa sakit, mengalami masa rawat inap yang lebih singkat, dan memiliki evaluasi negatif yang lebih sedikit dalam catatan perawat (Schaller, 2012, hal. 4).

Akses ke alam dapat diwujudkan melalui dua cara yakni secara alami dan buatan. Secara alami, akses ke alam dapat dilakukan dengan meletakkan bangunan pada lokasi yang masih alami dan restoratif seperti di pegunungan atau di tepi pantai. Akan tetapi mengingat fungsinnya akan penanganan keadaan darurat, bangunan rumah sakit harus berada di lokasi yang dekat dengan pemukiman dan aksesibel. Dalam hal ini lingkungan buatan berupa taman merupakan cara yang tepat untuk memberikan pasien akses ke alam (Ramadhani, Farkhan, \& Pramesti, 2018).

Sebuah taman pada bangunan rumah sakit hendaknya memiliki fungsi dan manfaat dalam menunjang penyembuhan pasien. Dalam istilah populer taman ini dikenal dengan sebutan healing garden. Healing garden atau Taman Penyembuhan merupakan sebuah taman yang dapat menyembuhkan suatu penyakit layaknya obat, mampu menurunkan emosi dan tingkat stress yang sangat tinggi melalui penyediaan ruangan untuk menenangkan pikiran, memperbaiki mental dan kesehatan emosi seseorang. Taman penyembuhan merupakan sebuah konsep yang sudah lama dikembangkan. Taman Penyembuhan pertama kali muncul di Eropa sekitar abad pertengahan. Pada abad XVII dan XVIII, sebuah pengobatan ilmiah mulai diterapkan pada ruang rumah sakit. Healing garden secara khusus ditujukan bagi orang yang sakit atau disabilitas, akan tetapi juga harus mampu memberikan manfaat bagi orang-orang yang dapat mengakses taman baik secara fisik maupun secara visual (Barmelgy, 2013, hal. 5).

Penggunaan kata penyembuhan dalam 'taman penyembuhan' merupakan suatu yang menunjukkan batasan tertentu, tapi bukan menekankan gagasan bahwa hal itu dapat menyembuhkan seseorang, imbalan tersebut lebih terkait dengan pengentasan stres dan kemampuan ruang untuk menenangkan, meremajakan atau memulihkan mental seseorang dan kesehatan emosional. Peran utama dari ruang ini adalah untuk memberikan perlindungan yang memungkinkan untuk meditasi atau untuk membangkitkan kualitas lain yang diinginkan oleh pengguna taman (Vapaa, 2002, hal. 3).

Peran utama dari healing garden adalah menyediakan semacam ruangan perlindungan layaknya cagar alam bagi tumbuhan, ruangan ini memungkinkan menjadi ruangan untuk meditasi bagi penggunanya sehingga membangkitkan kenangan atau memori yang menyenangkan (Vapaa, 2002).

Vapaa (2002) dalam tesisnya menyebutkan beberapa prinsip desain healing garden. Prinsip tersebut menjadi acuan bagi perancang untuk merancang suatu healing garden. Sebuah taman dapat disebut healing garden apabila telah memenuhi prinsip desain healing garden yakni healing garden harus dapat merangsang indera, mudah dipahami dan ditelusuri, aksesibel bagi pasien, bersifat terbuka, dan menyediakan tempat bagi satwa liar

Dengan demikian, healing garden pada rumah sakit ibu dan anak harus dapat mewujudkan prinsip desain healing garden dalam strategi desainnya agar healing garden dapat berfungsi optimal. 


\section{METODE}

Proses perancangan dan perencanaan rumah sakit ibu dan anak dilakukan dalam beberapa tahap. Kajian healing environment menjadi sudut pandang yang digunakan dalam memecahkan berbagai masalah terkait perancangan rumah sakit ibu dan anak.

Metode penelitian yang digunakan adalah metode triangulasi sumber. Metode ini dimulai dengan pengumpulan data dari berbagai sumber. Data dari beberapa sumber tersebut dipelajari kemudian dikelompokkan dan dicari persamaan dan perbedaannya. Setelah pengelompokan data selesai dilakukan , dilakukan eleminasi atau pengurangan data untuk mencari data yang relevan, mendukung dan masuk dalam lingkup pembahasan. Data yang telah diseleksi kemudian disajikan dengan metode deskripsi dengan menampilkan beberapa gambar sebagai contoh aplikasi desain. Kemudian dari data tersebut ditarik kesimpulan dan dicocokkan kembali dengan sumber-sumber data (Creswell, 2014). Sumber data yang digunakan adalah sebagai berikut.

a) Studi Literatur melalui buku cetak dan buku elektronik dan karya tulis ilmiah ang sudah diterbitkan. Buku yang digunakan antara lain Architectural Healing environments (Schaller, 2012), dan Health impacts of healing environments: a review of evidence for benefits of nature, daylight, fresh air, and quiet in healthcare settings (Berg, 2006). Karya tulis ilmiah yang digunakan yakni Tesis dengan judul Healing gardens: Creating Places for Restoration, Meditation, and Sanctuary (Vapaa, 2002), Jurnal Internasional dengan judul Healing garden's Design (Barmelgy, 2013).

b) Studi lapangan dengan melihat healing garden secara langsung pada Rumah Sakit Dr.Oen Solo Baru.

\section{HASIL DAN PEMBAHASAN}

Secara umum elemen healing garden dibagi menjadi dua yakni elemen keras dan elemen lunak. Elemen keras healing garden terdiri dari elemen pembentuk taman berupa pagar, tanah, bebatuan, jalan setapak, kolam, serta aksesoris pelengkap lainnya seperti kursi taman dan lampu taman. Elemen lunak healing garden merupakan elemen pengisi berupa vegetasi seperti rumput, pohon, dan bunga.

Perbedaan healing garden daripada taman biasa terletak pada efek restoratif atau efek penyembuhan yang dihasilkan. Efek penyembuhan bisa didapatkan apabila suatu taman sudah memenuhi prinsip-prinsip desain healing garden. Pada bangunan rumah sakit ibu dan anak, prinsip desain healing garden yang diterapkan pada elemen keras dan elemen lunak taman seperti pada penjelasan berikut.

Pertama, healing garden harus dapat merangsang kelima indera. Indera merupakan organ tubuh yang dapat merasakan efek restoratif yang ditimbulkan oleh healing garden secara langsung. Lima indera yang dirangsang antara lain indera penglihatan, indera pendengaran, indera peraba, indera penciuman dan indera perasa dirangsang dengan strategi desain taman dan pemilihan jenis vegetasi.

\subsection{Indera Penglihatan}

Pemilihan warna dan material merupakan cara yang paling tepat untuk merangsang indera penglihatan. Selain warna, pencahayaan alami pada taman juga mengambil peran besar dalam mempercepat proses penyembuhan. Biasanya warna yang digunakan dalam healing garden adalah warna yang lembut dan mendekati unsur alam. Warna-warna tersebut dipercaya dapat menenangkan dan menimbulkan rasa optimis pada diri pasien misalnya hijau, cokelat, merah muda, abu-abu dan putih. Warna ini akan menentukan pemilihan material. Material yang memiliki warna yang alami merupakan cara yang paling sesuai untuk membuat sebuah healing garden. Misalnya, material perkerasan pada jalan setapak dan titik kumpul dengan material alami seperti batu alam dan paving block. Material tersebut dinilai memiliki sifat menenangkan dan memberi kesan sejuk pada taman. 


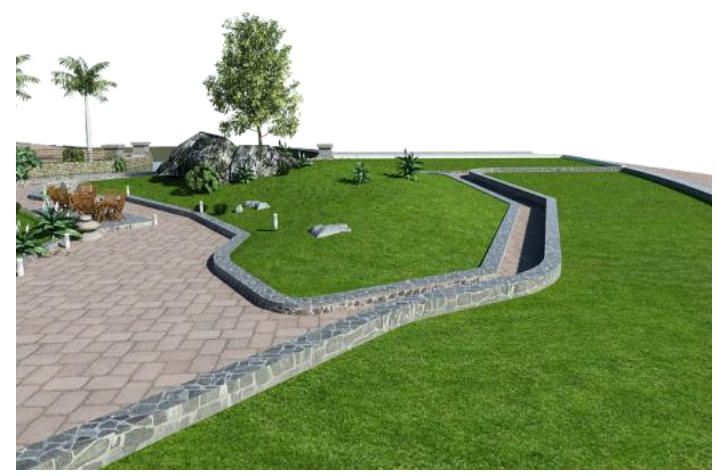

Gambar 1. Jalan Setapak yang Terbuat dari Perkerasan Batu

Cahaya matahari dapat besifat menguntungkan bagi kegiatan rumah sakit akan tetapi panas yang ditimbulkan oleh cahaya matahari seringkali mengganggu kenyamanan pasien dan staff rumah sakit. Cara dapat digunakan untuk mengurangi intensitas panas matahari pada healing garden yakni dengan menggunakan vegetasi peneduh.

Vegetasi peneduh bermanfaat ntuk mereduksi panas matahari siang pada taman. Sehingga healing garden tetap nyaman diakses meskipun saat matahari sedang terik. Akan tetapi peletakan vegetasi tidak boleh sampai menutupi cahaya matahari sepenuhnya. Karena pencahayaan alami khususnya di pagi hari dibutuhkan oleh pasien dalam proses penyembuhan.

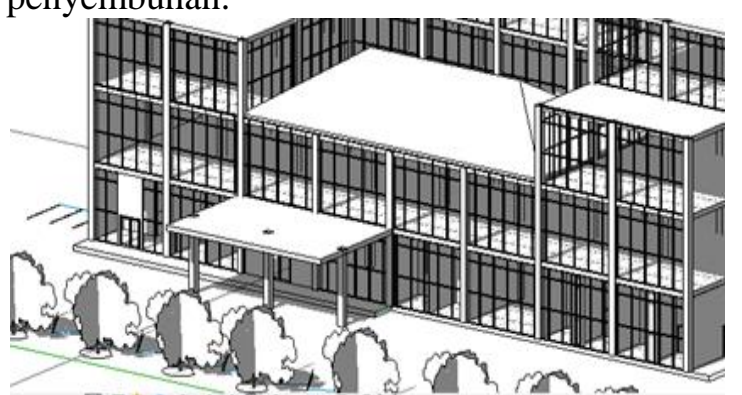

Gambar 2. Vegetasi Peneduh untuk Mengurangi Panas Matahari yang Masuk

Vegetasi peneduh biasanya merupakan jenis tumbuhan yang berdaun lebat, serta memiliki cabang yang menyebar ke segala sisi. Contoh vegetasi peneduh adalah pohon trembesi, pohon mahoni, dsb. Vegetasi peneduh diletakkan di dekat jalur pedest rian dan area istirahat. Contoh vegetasi peneduh adalah pohon trembesi dan pohon flamboyant
Bunyi terbagi menjadi dua yakni bunyi positif dan negatif. Bunyi positif dapat dihadirkan pada taman melalui suara hewan liar seperti kicauan burung, suara serangga, katak, dan hewan liar lainnya. Selain itu, suara angin sepoi - sepoi dan gemericik air dapat memberikan efek menenangkan bagi pasien dan penikmat healing garden lainnya. Untuk merangsang indera pendengaran, sebuah kolam ekosistem buatan yang di dalamnya terdapat teratai serta katak dapat menjadi opsi utama.

Ekosistem kolam dapat melibatkan bebagai jenis hewan liar di dalamnya seperti katak, ikan, dan burung. Suara katak di malam hari, suara kecipak air dari pergerakan ikan dan kicauan burung di pagi hari dapat memberikan efek positif bagi indra pendengaran manusia. Selain itu, pada ekosistem kolam dapat ditempatkan air mancur atau air terjun buatan yang menghasilkan suara gemericik air yang dapat membuat seseorang lebih merasa ceria dan bersemangat.

Keberadaan vegetasi yang dihembus angin juga dapat memberi efek positif bagi indra pendengaran pasien. Contoh vegetasi yang menimbulkan suara menyenangkan ketika dihembus angin adalah bambu kuning.

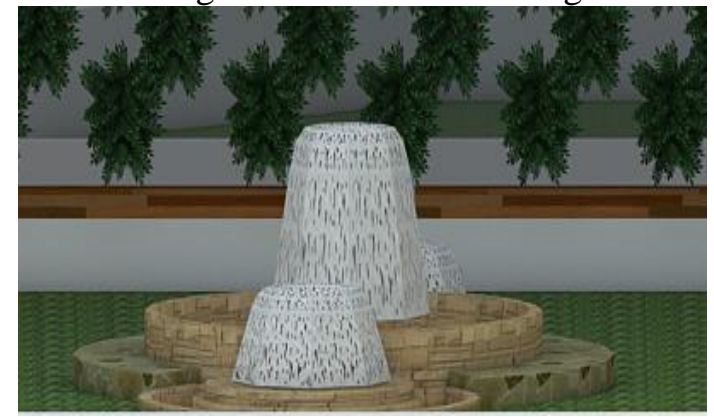

Gambar 3. Kolam Buatan

Suara negatif dikenal juga dengan sebutan noise atau kebisingan. intensitas kebisingan dapat dikurangi dengan meletakkan vegetasi dan pagar pada area batas healing garden. Pelatakan pagar dan vegetasi yang tepat bermanfaat untuk membelokkan suara dari kendaraan. Pengendalian kebisingan juga dapat dilakukan dengan menjauhkan ruang perawatan dari sumber kebisingan.

\subsection{Indera Pendengaran}




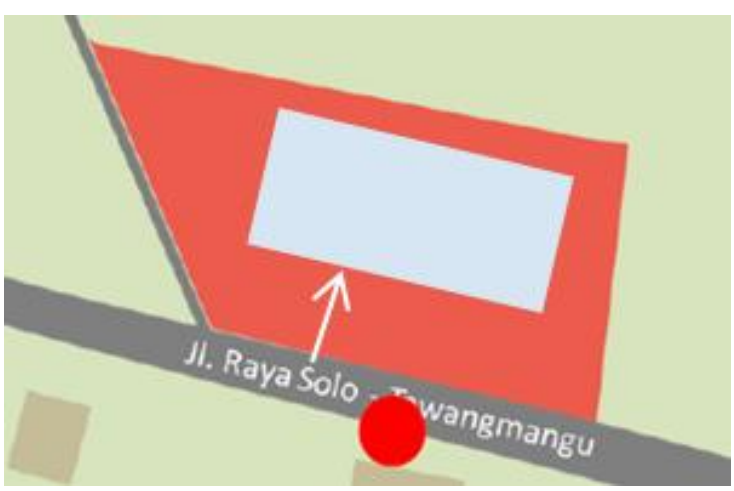

Gambar 4. Pengendalian Kebisingan dengan Menjauhkan Bangunan dari Sumber Kebisingan.

Green barrier atau pagar tanaman bisa dimanfaatkan untuk mengurangi kebisingan.

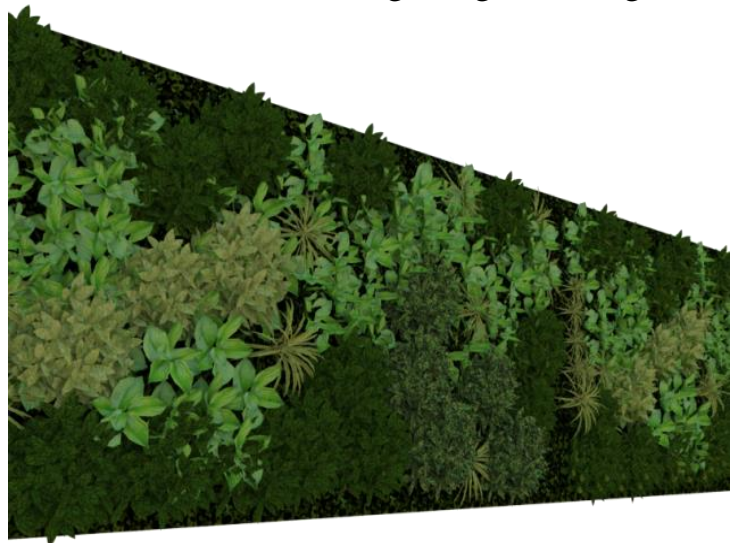

Gambar 5. Pagar Tanaman

\subsection{Indera Penciuman}

Indera penciuman dapat dirangsang dengan meletakkan vegetasi aroma terapi pada taman. Vegetasi aroma terapi merupakan vegetasi yang dapat mengeluarkan aroma yang mampu menenangkan pasien. Vegetasi ini biasanya berupa tanaman bunga-bungaan yang mengeluarkan aroma yang sedap contohnya bunga mawar, bunga melati, bunga sedap malam, dan bunga lavender. Lavender dipercaya mampu membantu penderita insomnia untuk lebih cepat tidur, begitu juga dengan wangi lemon yang memberikan relaksasi agar tidur lebih pulas, sedangkan mawar dapat membuat seseorang lebih merasa ceria dan bersemangat.

Bunga-bungaan ini diletakkan di dekat area istirahat dan tempat duduk agar dapat dinikmati secara optimal dan mampu mendorong naiknya kadar senyawa di dalam tubuh sehingga dapat memproduksi perasaan tenang dengan cepat.

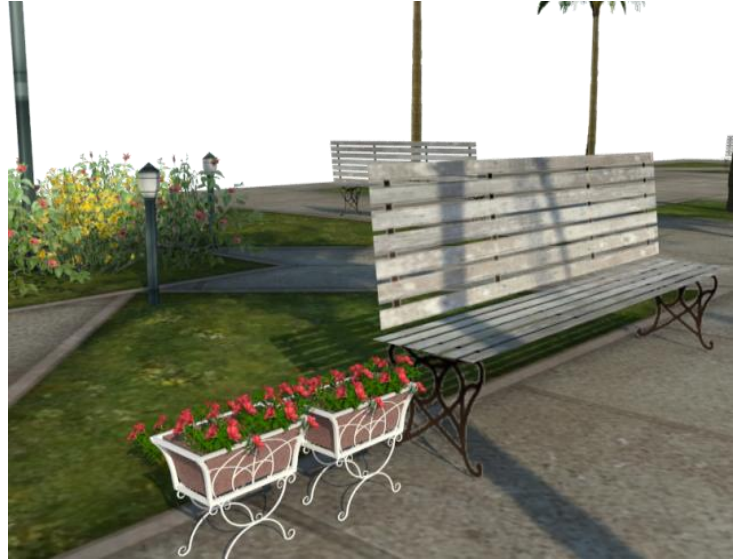

Gambar 6. Peletakan Vegetasi Aromaterapi di Dekat Tempat Duduk

Indera penciuman juga dapat dirangsang dengan menyediakan sumber udara segar bagi pasien. Ruang perawatan yang tertutup tidak memungkinkan bagi pasien untuk menikmati udara segar dengan optimal. Pasien seringkali ingin berjalan-jalan ke luar ruang perawatan untuk menikmati udara segar. Udara segar dapat dihasilkan melalui proses fotosintesis tumbuhan. Proses fotosintesis menyerap polutan berupa gas karbon dioksida dan menghasilkan oksigen yang dibutuhkan paruparu manusia. Tanaman hijau yang tinggi dan rimbun akan menghasikan oksigen yang lebih banyak.

\subsection{Indera Peraba}

Penggunaan vegetasi yang memberikan respon terhadap sentuhan dapat merangsang indera peraba pasien untuk menyentuhnya. Tumbuhan yang peka terhadap sentuhan adalah tumbuhan tigmonasti. Tigmonasti merupakan gerak tumbuhan yang disebabkan adanya sentuhan atau getaran.Tigmonasti disebut juga seismonasti. Saat rangsangan sentuhan datang, terjadi aliran air menjauhi bagian yang disentuh tersebut. Aliran air tersebut menyebabkan kadar air sel-sel motor di daerah sentuhan berkurang dan tekanan turgor mengecil Contoh vegetasi tigmonasti adalah putri malu. Keberadaan taman bunga dengan warna yang beraneka ragam juga bisa diaplikasikan. Taman bunga juga menghadirkan tekstur yang beragam sehingga mengundang pengguna taman untuk menjelajahi lebih dalam untuk menyentuh secara langsung. Rumput dandelion juga dapat 
menimbulkan rasa penasaran pasien untuk menyentuh dan meniup bunganya.

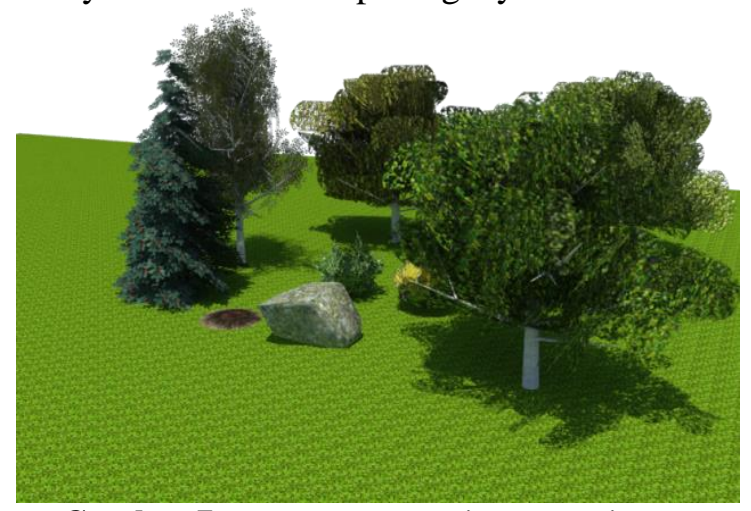

Gambar 7. Penggunaan Jenis Vegetasi yang Beragam

\subsection{Indera Perasa}

Indra perasa menjadi terganggu pada saat pasien mengalami sakit ataupun menerima pengobatan. Hal ini biasanya ditunjukan dengan berubahnya rasa makanan maupun minuman saat dikonsumsi. Berubahnya rasa makanan pada lidah seringkali mengurangi nafsu makan pasien. Buah dan sayur merupakan makanan yang mampu menyegarkan mulut.

Peletakan tanaman yang dapat dimakan merupakan salah satu cara yang dapat dilakukan untuk merangsang indera perasa. Tanaman yang dapat dimakan dapat berupa sayur dan buah-buahan. Sayur dan buahbuahan yang ditanam pada taman memungkinkan bagi pasien untuk merasakan pengalaman pada indera perasa mereka dengan cara yang berbeda.

Terdapat berbagai cara untuk menanam buah dan sayuran. Salah satu cara yang sederhana dan sedang digemari adalah penanaman buah dan sayur dengan cara hidroponik. Vegetasi buah dan sayur yang cocok ditanam secara hidroponik misalnya selada, stroberi, tomat, dan sebagainya. Tanaman hidroponik dapat ditanam secara vertikal dan membuatnya menjadi vertical garden untuk menambah nilai estetika.

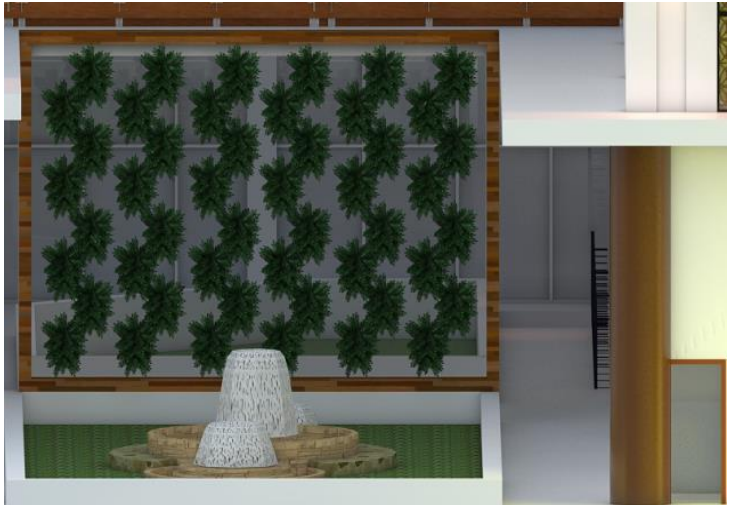

Gambar 8. Tanaman Hidroponik yang Ditanam secara VertiKal

Kedua, sebuah healing garden harus mudah ditelusuri dan dikenal. Desain taman yang tidak membingungkan akan memudahkan pasien untuk menemukan jalan masuk dan keluar dari taman. Penggunaan tanda dan simbol akan memudahkan dalam wayfinding.

Peletakkan titik temu pada jalur-jalur taman memudahkan pengguna taman untuk menemukan jalan keluar. Selain itu titik-titik temu dapat dimanfaatkan sebagai tempat istirahat bagi pengguna taman dan sebagai tempat untuk menikmati taman. Pada titik temu dapat diletakkan kursi taman sebagai tempat duduk dan dapat digunakan oleh pasien untuk beristirahat jika lelah berjalan pada taman.Penggunaan lampu taman juga memungkinkan agar taman tetap dapat diakses pada malam hari.

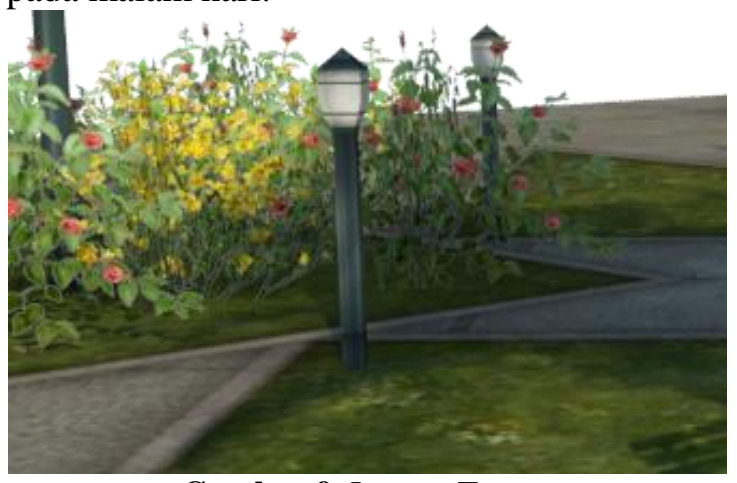

Gambar 9. Lampu Taman

Ketiga, rancangan sebuah healing garden harus memikirkan tentang aksesibilitas bagi para pasien. Pasien rumah sakit ibu dan anak didominasi oleh wanita yang baru saja melahirkan. Kondisi tubuh wanita paska melahirkan masih lemah dan seringkali membutuhkan kursi roda untuk keluar dari kamar perawatan. Selain itu, pasien anak-anak 
yang dalam kondisi sakit juga sering menggunakan alat bantu untuk berjalan-jalan di taman. Desain taman yang aksesibel memungkinkan bagi semua pasien untuk dapat mengakses taman.

Bagi pasien yang dapat berjalan normal, lebar akses jalan setapak minimal 1,5 m untuk lalu lintas taman. Sedangkan untuk pasien kursi roda lalu lintas dua arah, lebar minimal yang dianjurkan adalah $2 \mathrm{~m}$. Penggunaan tekstur yang berbeda di pinggir jalan untuk membantu pasien dengan daya penglihatan yang kurang sehat untuk mengenali kapan mereka dari jalan. Hindari bahan yang menyilaukan, karena cahaya bisa sangat mengganggu. Kemiringan jalan tidak boleh melebihi $2 \%$ atau perbandingan kemiringan tidak melebih I 1:20.

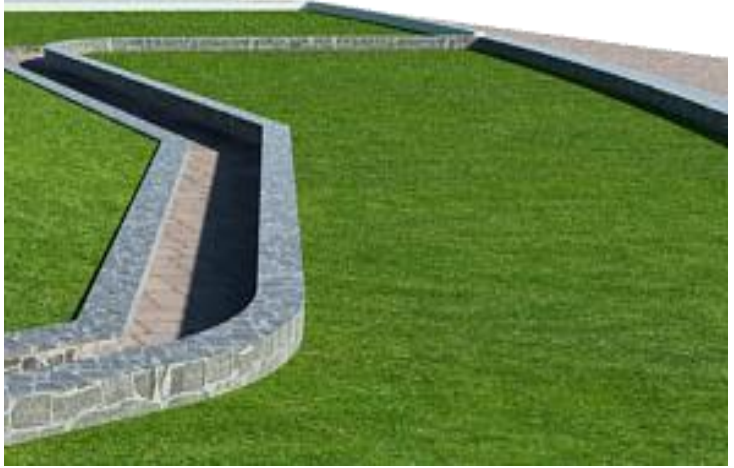

Gambar 10. Akses Jalan Taman

Keempat, Sebuah healing garden hendaknya bersifat terbuka dan dapat diakses oleh banyak orang. Keberadaan healing garden sebaiknya tidak hanya memberi manfaat bagi pengguna rumah sakit ibu dan anak akan tetapi juga kepada orang di sekitar rumah sakit ibu dan anak. healing garden yang terbuka secara visual mampu memberikan efek positif pada orang lain selain pengguna rumah sakit.

Agar dapat diakses oleh orang lain, healing garden juga diletakkan di area depan rumah sakit ibu dan anak. Peletakan healing garden di area depan memungkinkan bagi pengguna jalan untuk ikut menyaksikan dan menikmati healing garden.

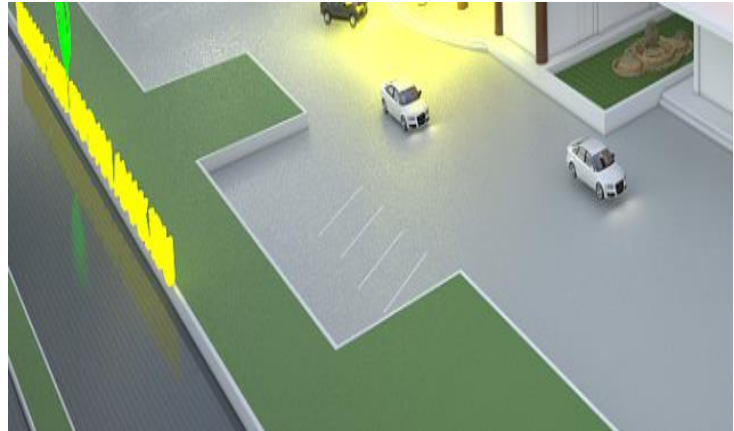

Gambar 11. Taman di Area Depan Rumah Sakit Ibu dan Anak

Kelima, menyediakan tempat bagi satwa liar. Beberapa bagian dari healing garden harus berada pada ruang terbuka hal ini memungkinkan bagi satwa liar untuk ikut hidup dan menikmati healing garden. Kemudian pasien sebagai sasaran utama healing garden dapat menikmati satwa liar tersebut seperti kicauan burung yang mampu memberikan ketenangan.

Sebuah taman yang baik tidak hanya menjadi tempat relaksasi bagi manusia akan tetapi juga sebagai rumah bagi hewan liar. Keuntungan keberadaan hewan liar dalam healing garden menambah kesan alami pada healing garden. Lingkungan buatan yang dirancang juga dapat berwujud seolah-olah ekosistem alami yang di dalamnya terjadi proses interaksi antara manusia, hewan, dan tumbuhan.

Penyediaan tempat bagi hewan liar dapat dilakukan dengan meletakkan tanaman bunga yang mengeluarkan nektar, sehingga serangga seperti kumbang dan burung kolibri akan hinggap untuk menghisap nektar dari bunga tersebut. Di samping itu, untuk menarik hewan liar juga dapat dilakukan dengan peletakkan kolam yang bisa menjadi tempat hidup bagi katak dan ikan kecil. burung pipit juga senang membangun sarang mereka pada dahan pohon. Pohon yang besar dan rimbun merupakan tempat yang cocok untuk membangun sarang.

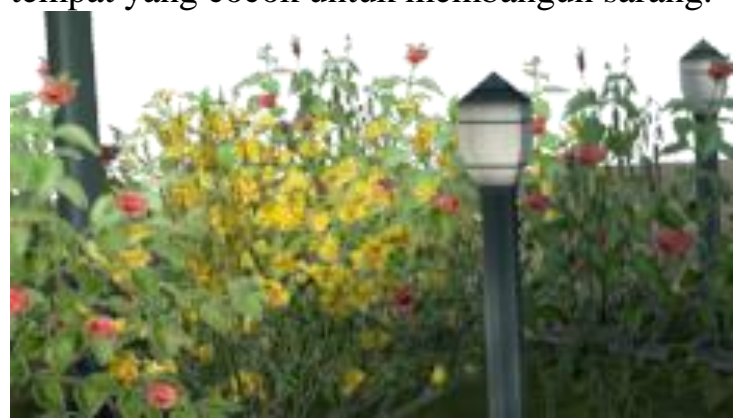


Gambar 12. Taman Bunga yang Menghasilkan Nectar

\section{KESIMPULAN}

Pada strategi desain rumah sakit ibu dan anak, healing garden dirancang dengan menerapkan prinsip desain healing garden pada elemen keras dan elemen lunaknya. Pertama, healing garden harus dapat menstimulasi lima indera. Stimulasi indera penglihatan dilakukan dengan pemilihan warna dan material yang alami, serta pemanfaatan cahaya matahari. Stimulasi terhadap indera pendengaran dilakukan dengan pengaplikasian kolam ekosistem buatan serta pengendalian kebisingan. Stimulasi terhadap indera peraba dilakukan dengan penggunaan vegetasi yang peka terhadap sentuhan. Stimulasi terhadap indera perasa dilakukan dengan peletakan vegetasi yang dapat dimakan. Serta stimulasi terhadap indera penciuman dengan peletakan tanaman bungabungaan di dekat kursi taman. Kedua, penggunaan tanda dan simbol pada healing garden bertujuan agar taman mudah dipahami dan ditelusuri. Ketiga, taman bersifat aksesibel bagi pasien dengan penentuan lebar jalan dan penggunaan ramp. Keempat, taman bersifat terbuka dengan meletakkan beberapa area healing garden di area depan rumah sakit ibu dan anak. Kelima, taman menyediakan tempat bagi satwa liar dengan meletakkan healing garden pada ruang yang terbuka.

\section{REFERENSI}

Barmelgy, H. E., Dr. (2013). Healing Gardens' Design. Contemporary Research Center Publisher, 1 No. 6.

Berg, A. E. van den. (2006). Health impacts of healing environments: a review of evidence for benefits of nature, daylight, fresh air, and quiet in healthcare settings. Groningen: Foundation 200 years University Hospital Groningen.

Creswell, J. W. (2014). Research design: qualitative, quantitative, and mixed methods approaches (4th ed). Thousand Oaks: SAGE Publications.

Kementerian Kesehatan. (2010). Keputusan Menteri Kesehatan No. 340 Tentang Klasifikasi Rumah Sakit.
Kurniawati, F. (2007). Peran Healing Environment Terhadap Proses Penyembuhan. UGM: Yogyakarta.

Ramadhani, G. E., Farkhan, A., \& Pramesti, L. (2018). The Design Application of Physical Outcome's Theory on The Hospital of Mother and Child In Surakarta. Arsitektura Universitas Sebelas Maret, 16, 10.

Schaller, B. (2012). Architectural Healing Environments. Syracuse University Surface.

Vapaa, A. G. (2002). Healing Gardens: Creating places for restoration, meditation, and sanctuary. Virginia Tech.

Zhafran, D. B., Hardiyati, H., \& Pramesti, L. (2017). Balai Kesehatan Jiwa dengan Pendekatan Healing Environment di Surakarta. Arsitektura Universitas Sebelas Maret, 15, 149. 